\title{
Research on the Teaching Reform of Marine Navigation Course Based on "MOOC \& Flipped Classroom"
}

\author{
Shaoyi Guo, Fanyi Kong \\ Shandong Jiaotong University, Weihai Shandong, 264200, China
}

Keywords: MOOC, Flipping classroom, Marine Navigation, Knowledge Network.

\begin{abstract}
This paper analyzes the characteristics of Marine Navigation courses, which builds a knowledge network of course by decomposing the key knowledge points according to DACUM's professional competence and conducts "MOOC+ flipping classroom" to carry out teaching reform research on Marine Navigation courses in order to establish a diversified course assessment method. Meanwhile, through in-depth fusion of information technology and Marine Navigation courses, we will explore teaching models and teaching methods that are suitable for advanced navigation education and meet the requirements for training advanced application-oriented navigation talents.
\end{abstract}

\section{Introduction}

With the rapid development of "Internet accelerated speed" and information technology, new educational technologies and teaching concepts such as MOOC and flipping classrooms have brought new ideas for the teaching reform of the Navigation professional course. The so-called MOOC is the use of "Internet accelerated speed" and information technology to share course resources on the Internet platform so that students could use the online platform to watch teaching videos and complete the Learning Tasks in the task list, which complete knowledge transfer through student experience and interactive communication. Flipped Classroom is the use of information technology in teachers to impart the knowledge before class, and teachers and students can make the face to face communication in classroom and guide students to internalize and absorb knowledge. Among them, students are autonomous learners to actively internalize knowledge, then teachers are learning instructor, resources Provider, organizer of classroom activities ${ }^{[1]}$.Therefore, the teaching reform of Marine Navigation Course of the navigation technology specialty based on the "MOOC \& Flipped Classroom" has an important role in improving classroom efficiency, enhancing teacher-student interaction, broadening the depth of exploration issues, and fostering the capabilities of practice and innovation .

\section{The Features of "Marine Navigation" course}

"Marine Navigation" is a core course of the navigation technology specialty. It focuses on navigation Fundamental knowledge, ship position fixing and navigation, route planning, navigation and sailing, etc., and develops the skills for Ship Safety Navigation. According to the requirements of the STCW Convention Manila Amendments, "Marine Navigation" which combines the meteorology and adds the new electronic charts is a comprehensive course that combines both theory and practice. The curriculum system is huge, and and its content and information is numerous and large, and it has a strong abstract synthesis. The students also need to pass the examination and practical assessment of the National Maritime Bureau [2]. However, the traditional classroom teaching is based on teachers' instillation of knowledge and lack of the situational awareness of actual working situation. It is impossible to penetrate all knowledge points of "Marine Navigation" into various tasks in the officer's watching work, resulting the difficulty in understanding or learning to use. In the classroom teaching, teachers only focus on the teaching of this course, seldom involving the expansion of 
technological frontier knowledge, such as the development status and trends of E-navigation, fleet operations center, electronic chart publications, polar air navigation and other new navigation technologies and new concepts. While the Practical project evaluation examination focused on training before the assessment exam, students mainly rely on short-term memory to pass the assessment of the Maritime Affairs Bureau, but they fail to meet the requirements for consolidation of practical skills. Therefore, it is difficult for students to have a holistic understanding of the "Marine Navigation" knowledge system, meanwhile, the depth of systematic and integral understanding of knowledge content and the cognition of relevance and application of knowledge points and operation items are insufficient, the knowledge and application of knowledge points and operation items so as not to turn knowledge into practice. Even after boarding, students can't apply what they have learned to practical work.

"MOOC \& Flipped Classroom" is based on open education of the network learning. The students are assisted for completing knowledge learning through MOOC and information technology before class. Under the meticulous organization and reasonable guidance of the teacher, the internalization of knowledge is completed in the classroom. At the same time, relying on powerful information and platform, teachers and students can interact in real time to achieve seamless integration inside and outside the classroom. In order to strengthen the requirements of the Marine Navigation course of "fundamentality, practicability, practicalness and innovation", the "MOOC \& Flipped Classroom" will be used to reconstruct the knowledge network of Marine Navigation course, and carried out the Reform of course teaching content and teaching method reform in order to meet the requirements of cultivating the "Knowledge, Competence, and Quality" of the three-in-one advanced application-oriented navigation talents.

\section{The Teaching Reform Principles of "MOOC \& Flipped Classroom"}

The teaching reform of "MOOC \& Flipped Classroom" should follow the principles of resource diversity, personalized guidelines, moderate tasks, and process evaluation ${ }^{[3]}$.

\subsection{The principle of resource diversity}

Teachers should try to meet different students' requirements for resources as much as possible, such as video, case, text, PPT, etc. Teachers should deal with the selection and classification of resources so that the students of skill levels can get help in learning, easy to find and study.

\subsection{The principle of personalized guidelines}

Teachers need to get hold of the students' learning situation before class and understand the problems so that they can provide some targeted guidance in class.

\subsection{The principle of moderate tasks}

The teacher conducts the Pupil description according to the tasks of each lesson and measures the student's ability and time so that the amount of tasks is moderate and the difficulty is moderate.

\subsection{The principle of process evaluation}

Teachers formulate the diversified evaluation indexes according to the characteristics of the course, and turn one-time examination assessment into multiple assessments. At the same time, the importance of the process evaluation, the performance of group, self-evaluation and mutual evaluation should be attached.

\section{Building a teaching mode of Marine Navigation course based on "MOOC \& Flipped Classroom"}

The Marine Navigation Course are highly practical and applicable. Focusing on the training of advanced application-oriented navigation talents, the key knowledge points of the Marine Navigation Course are divided and the mutual relations among the knowledge points are analyzed as well as the 
course knowledge network is constructed, which based on the analysis of the DACUM maritime professional competence. Then the use of "Mu tuition + flip classroom" for the teaching reform of Marine Navigation Course can be implemented through the use of "MOOC \& Flipped Classroom", as shown in Figure 1.

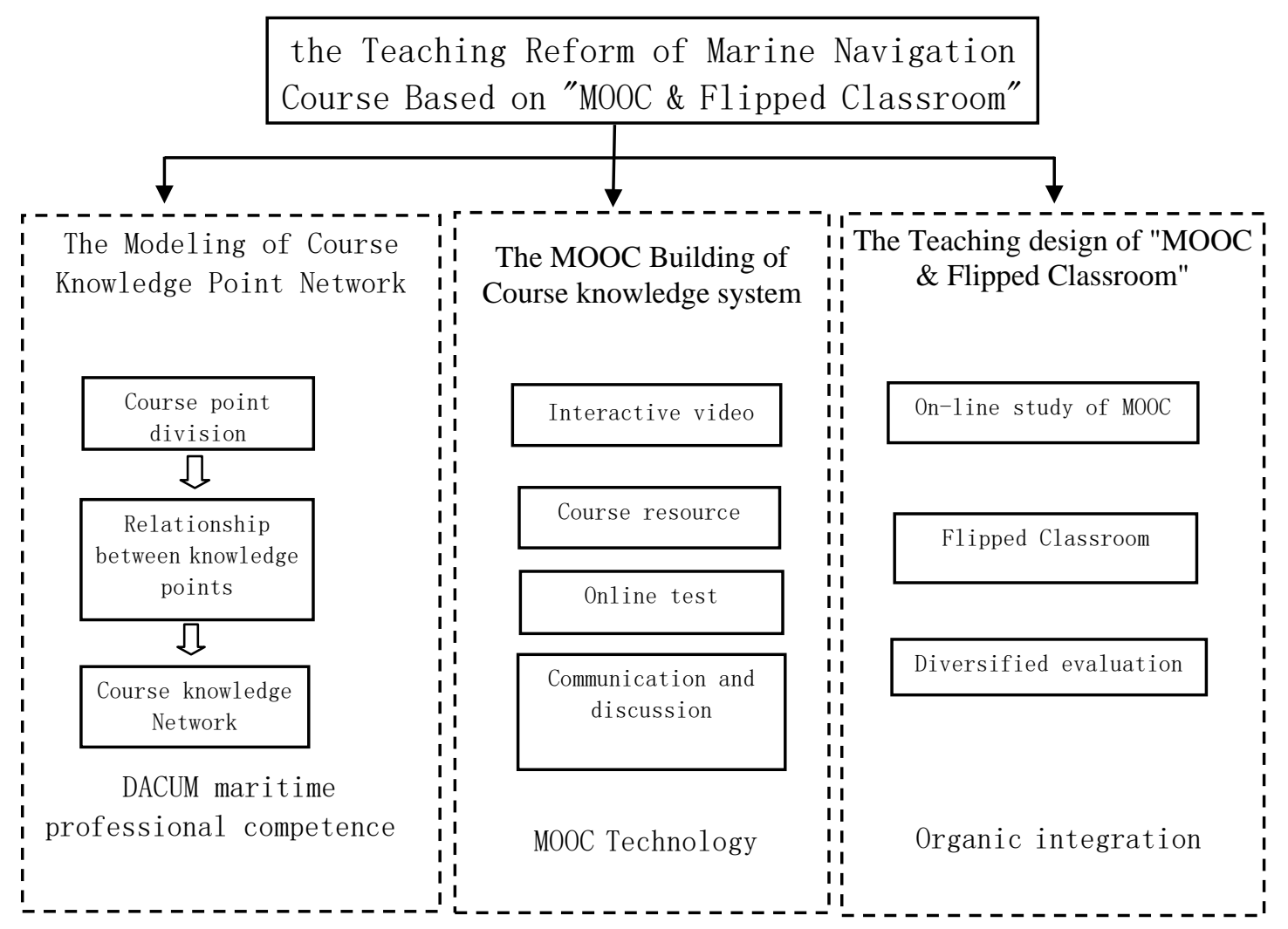

Figure 1. the Teaching Reform of Marine Navigation Course Based on "MOOC \& Flipped Classroom"

\subsection{Using Mind Maps to Build a Knowledge Network of Marine Navigation Course}

Mind maps can develop students' habits of systematic learning and thinking to studying new knowledge faster, and integrating old knowledge so as to enable people to have superior learning abilities $^{[4]}$. The building of a course knowledge network is conducive to the construction of MOOCs and the learning of students' courses, and to the mastery of knowledge points. Focusing on the training of advanced application-oriented navigation talents, the key knowledge points of the Course are divided and the logical relationships between various knowledge points are analyzed to organize closely various teaching topics and knowledge points, which based on the analysis of the DACUM maritime professional competence. At the same time, the knowledge network of Marine Navigation Course is built. By using the mind maps in order to solve the lack of systematic problems in MOOC course construction focusing on fragmented knowledge. Figure 2 is the map of a ship positioning fixing knowledge network using mind maps. It adopts the divergent thinking mode to present the knowledge structure in a comprehensive manner. The teacher grasps the teaching content as a whole and clarifies the teaching ideas to define the teaching focus and difficulties. 


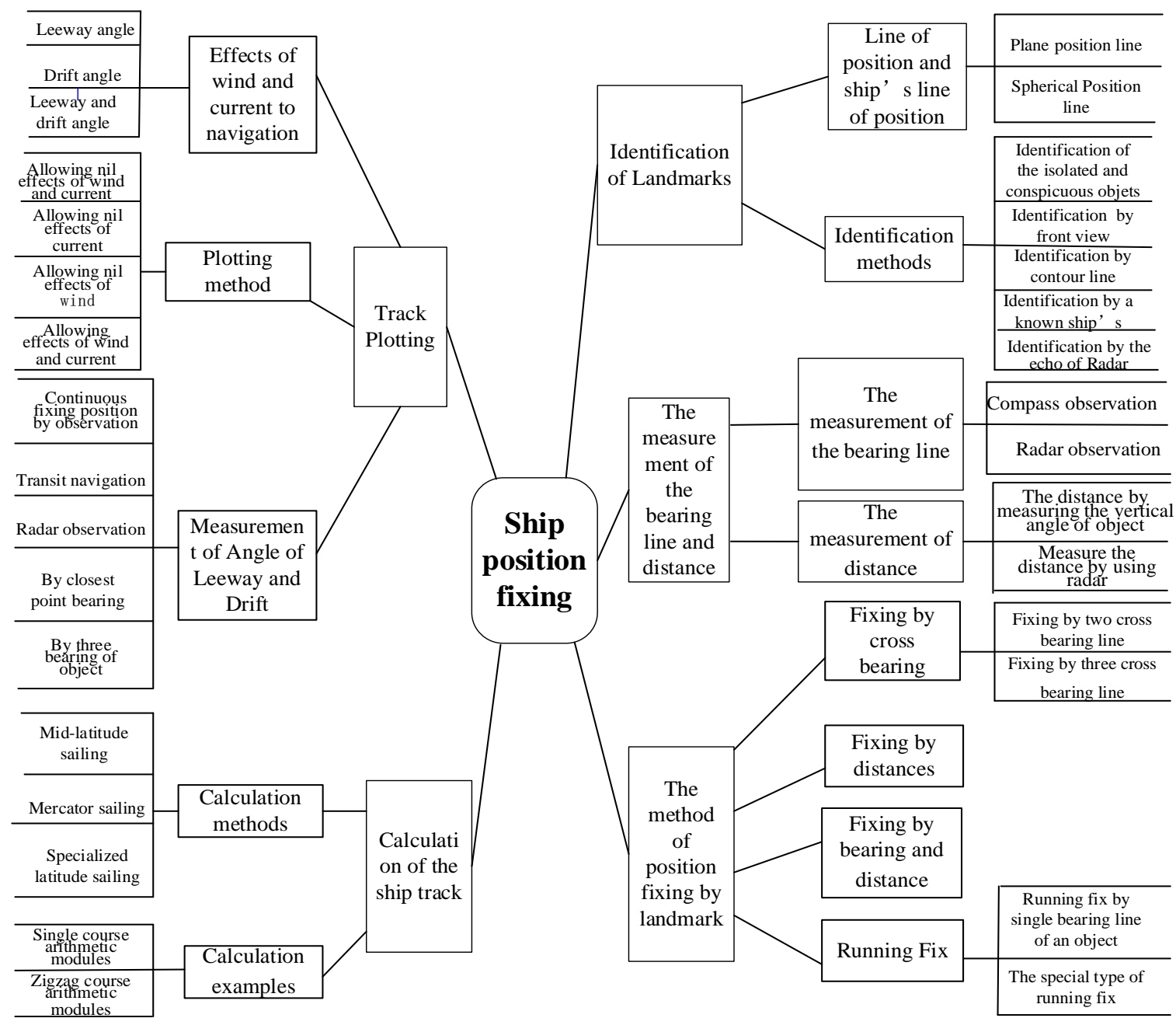

Figure 2. Ship positioning fixing knowledge network

\subsection{Building a MOOC network resources to optimize the teaching of "Marine Navigation"}

The MOOC construction of "Marine Navigation" Course includes interactive video, course resources, online test, communication and discussion. According to the knowledge network of Marine Navigation course, the teacher can decompose a series of small knowledge points and systematically record all kinds of micro-video in 8-15 minutes which is equipped with relevant lesson plans, instructional design, practice tests, and review comments, etc. to form a micro-learning unit and design The corresponding practice links of knowledge points so that students are allowed to consolidate the content of knowledge through practice after the completion of a single knowledge point to explain the task. Taking the example of knowledge module of the ship's Position Fixing by landmark, students can conduct self-study through the MOOC network platform. The teacher enumerates the difficult points and explains them. Then the sub-groups are executed in the navigation simulator laboratory to accomplish the selection of fixing targets, the identification of targets, the measurement of bearing and distance of targets, ship position fixing and other important objectives. The teacher sets up corresponding questions according to each step. Meanwhile, each group needs to complete the questions in sequence during the process of task, which act as a process evaluation index, then the entire process of task's completion and the accuracy of the results are completely preserved, making it easier for teachers to conduct teaching analysis and student assessment.

\subsection{Forming the online and offline mixed teaching mode based on the "MOOC \& Flipped Classroom"}

Using MOOC \& Flipped Classroom, a mixed teaching mode combining online self-study and offline classroom teaching is adopted. Students can conduct online self-study through the network 
platform which can record students' learning trajectories, homework assignments, pre-tests, classroom task assignments, teacher-student's interactive discussions, students' difficult questions, test scores and students' network learning processes. Teachers can analyze the results of students' self-learning according to the above data, which could ask specific questions in the classroom and inspire students to discuss for following the guidance and skillfully imparting knowledge to students. What's more, teachers can adjust teaching progress and teaching arrangements according to the effect of classroom discussion. Among them, teaching process has always reflected the student's dominant position to ensure the effective convergence of online learning and classroom discussion. Taking the teaching of navigation fundamental knowledge as an example, teachers can publish the recorded teaching videos on the platform before class, then allow students to prepare for independent study so that students have a basic understanding of the basic concepts, ideas, contents, and methods of navigation basic knowledge as well as encourage students to collect independently relevant data.in addition. Teachers organize students to discuss and supplement the key and difficult points of knowledge to enhance students' understanding and mastery for new knowledge in the classroom. Another example is the teaching method of the navigation in narrow channel which can be selected to be close to the actual navigation simulation environment for on-the-spot interaction. In this scene, the students are grouped to perform role-play, and the teacher should take part in the role-play. After that, the students are organized to discuss the problems found in the scene simulation. In the end, the teacher introduces the knowledge of the navigation in narrow channel based on the scenario simulation for deepening the students' understanding with the actual sailing case.

\subsection{Using MOOC platform to establish diversified course assessment method}

The MOOC platform should be fully applied to establish a diversified assessment method of flipping classrooms and turn one-time test assessment into multiple assessment, which focus on the combination of formative assessment, summative assessment, quantitative assessment and qualitative assessment. The assessment of Marine Navigation course can take the following forms: final-examination(50\%) + process assessment (20\%) + daily performance (10\%) + MOOC learning (20\%).The final comprehensive assessment will be determined through various indexes which be decided by the situation of online MOOC video learning, homework and test completion, forum and discussion groups' participation as well as work and testing in offline flipped classroom , class discussion, classroom presentation and course examination[5]. According to the requirements of the teaching outline for the course and teaching content, the focus and scope of the assessment could be determined for focusing on the student's flexibility, practical skills and innovation capability in the use of key knowledge of Marine Navigation course.

\section{Conclusion}

In the process of the teaching reform of Marine Navigation course based on "MOOC \& Flipped Classroom", the course group should continue to improve the construction of MOOC and provide students with a wealth of teaching resources in the online platform in order to create an network learning environment for on-line study and communication for students and enhance students' awareness of innovation and cooperation. In MOOCs age, the Marine Navigation serves as the core courses of the navigation technology professional. So it is necessary to promote the deep integration of information technology and Marine Navigation courses to explore teaching modes and teaching methods that are suitable for advanced navigation education and improve the quality of teaching so that train many high-quality application-oriented navigation talents for the rapid development of China shipping industry.

\section{Acknowledgement}

This research was financially supported by the Study on the Construction of the Core Course of Navigation Majors-Taking "Marine Navigation" as an Example (No. JG201501). 


\section{References}

[1] CHEN Yi, ZHAO Chen-ling. An Instruction Design and Application Research Based on the Flipped Classroom Model, Modern Educational Technology, 2014(2), 49-54.

[2] Tao Nie, Zhiyuan Dong etc.. Design and Implementation of "Marine Navigation" Informational Teaching, Maritime Education Research, 2015(4), 91-94.

[3] CHEN Yi. A Design and Application Research: The Flipped Classroom Instructional System Based in Blended Learning, Central China Normal University, 2014.05:16-17.

[4] BoFeng, Yunrong Yan etc. The Application of Mind Map in the Teaching of "Marine Navigation" Course, Maritime Education Research, 2014(3): 63-65.

[5] ZHANG Mu-lin, SUN Xiao-jun. MOOC-based Flipped Classroom Teaching Model for Follow-up College English Courses, Modern Educational Technology, 2015(8):81-87. 